\title{
IMPLEMENTASI WEB SERVICE DALAM PENGEMBANGAN SISTEM INFORMASI AKADEMIK BERBASIS MOBILE PADA STIKES NANI HASANUDDIN MAKASSAR
}

\author{
Marwa Sulehu', Ardhyansyah Mualo ${ }^{2}$ \\ Sekolah Tinggi Manajemen Informatika dan Komputer \\ Program Studi Teknik Informatika, STMIK AKBA MAKASSAR \\ Email: ${ }^{1}$ msulehu@gmail.com, ${ }^{2}$ mualoardhyansyah@gmail.com
}

\begin{abstract}
ABSTRAK
STIKES NANI HASANUDDIN merupakan salah satu perguruan tinggi Swasta yang ada di kota Makassar yang bergerak dibidang kesehatan, untuk mengelolah data yang berhubungan dengan informasi akademik, meliputi data mahasiswa, data dosen, rekaman hasil kuliah, kurikulum dan jadwal perkuliahan. SIAKAD yang berbasis smartphone sangat dibutuhkan bagi para mahasiswa, untuk meningkatkan kualitas pelayanan maka dibutuhkan adanya sebuah sistem informasi yang mampu memonitoring yang dapat membantu proses pengolahan tersebut. Salah satunyayaituuntuk mengembangkan sistem informasi akademik yang lebih efektif, efisien, dan mudah dalam mengaksesnya.Penelitian ini bertujuan untuk merancang dan mengimplementasikan Web Service dalam pengembangan Sistem Informasi Akademik berbasis mobilePada STIKES NANI HASANUDDIN.Data ini di peroleh melalui Penelitian lapangan Penelitian Pustaka Wawancara.Hasil dari penelitian ini menunjukan bahwa sistem dapat berjalan dengan baik, dan lebih memudahkan mahasiswa mengetahui informasi mengenai akademik terutama Nilai serta menjadi media informasi bagi mahasiswa.
\end{abstract}

Kata Kunci :StikesNani, sisteminformasi,Implementasi, web service, Android

\begin{abstract}
STIKES NANI HASANUDDIN is one of the private colleges that are in Makassar city engaged in health, for dissemination-related academic information, including student data, data recording result lecturer, lectures, lecture schedule and curriculum. SIAKAD based smartphone is urgently needed for the students, to improve the quality of service required the existence of an information system that is able to monitor which can help the processing process. One of which is to develop the academic information system more effective, efficient, and easy to access. This research aims to design and implement a Web Service in the development of mobile-based Academic information systems At STIKES NANI HASANUDDIN. This data is obtained through research in the field of research the library interview. The results of this research show that the system can run well, and makes it easy for students to know more information about the academic Value as well as being primarily a medium of information for the student.
\end{abstract}

Keywords: StikesNani, information systems, implementation, web services, Android

\section{PENDAHULUAN}

STIKES NANI merupakan salah satu perguruan tinggi yang berada di kota makassar yang bergerak di bidang kesehatan. Informasi mengenai kampus menjadi salah satu hal yang sangat penting baik dalam lingkup internal maupun eksternal. Bentuk Informasi yang disajikan saat ini dalam bentuk website, sehingga masih perlu menggunakan web browser untuk mengakses situs websitenya. Kelebihan dari pengembangan sistem 
informasi akademik ini diharapkan mampu memberikan nontifikasi atau pemberitahuan pesan baru mengenai data yang telah diupdate oleh admin dengan mengimplementasikan web service. Web service memungkinkan untuk melakukan proses pertukaran data untuk sinkronisasi data antar sistem yang telah ada(Sutanta \& Mustofa, 2014). Dimana web service akan bertindak sebagai server dan smartphone sebagai pihak client yang mengakses data diserver tersebut.Web service adalah sebuah software yangdirancang untuk mendukung interoperabilitas interaksi mesin-ke-mesin melalui sebuah jaringan(Lucky, 2008)(Sutanta \& Mustofa, 2014).

Setelah melakukan penelitian tentang jumlah pengguna smartphone di lingkungan kampus STIKES NANI dari angkatan 2013-2016 rata-rata pengguna smartphone dari $10 \%$ orang hanya $9 \%$ yang menggunakan smartphone dan $1 \%$ yang tidak menggunakan smartphone, inilah yang menjadikan alasan mengapa pengembangan sistem infomasi akademik beralih menjadi aplikasi android. Dengan android maka informasi diharapkan lebih mudah untuk diakses.

Dari permasalahan tersebut maka akan di lakukan penelitian dengan judul: "Implementasi Web Service dalam pengembangan Sistem Informasi Akademik Berbasis Mobile Pada STIKES NANI HASANUDDIN".

\section{A. RumusanMasaah}

Berdasarkan Latar belakang maka rumusan masalah dari penelitian ini adalah sebagai berikut :

1. Bagaimana perancangan sistem informasi akademik berbasis mobile pada STIKES NANI?
2. Bagaimana pengimplementasian web service dalam sistem informasi akademik STIKES NANI berbasis mobile?

\section{B. TujuanPenelitian}

Tujuan dari penelitian ini berdasarkan pada rumusan masalah yang telah dibuat sebelumnya yaitu :

1. Merancang Sistem Informasi Akademik berbasis Mobile pada Stikes Nani Hasanuddin.

2. Mengimplementasikan web service dalam Sistem Informasi Akademik Stikes Nani hasanuddin berbasis mobile.

\section{METODE PENELITIAN}

1. metode pengumpulan data dilakukan dengan beberapa cara yaitu :

a. Observasi

Observasi yang dimaksudkan dalam penelitian ini yaitu melakukan penelitian secara langsung di dalam bidang kerja, sehingga peneliti dapat memahami dan mengetahui masalah apa saja yang ada di dalamnya.

b. Studi Literatur

Metode pengumpulan data dilakukan melalui beberapa sumber seperti perpustakaan atau literaturliteratur yang akan menjadi pendukung bagi penelitian.

c. Wawancara

Metode pengumpulan data ini dilakukan dengan memberi 
pertanyaan secara langsung kepada

pihak kampus khususnya BAAK

2. Use Case Diagram

Diagram UseCase atau

UseCasediagram menyajikan interaksi antara use case dan aktor. Diagram UseCase mempunyai beberapa bagian penting seperti Actor, Use Case,

Undirectional atau Relasi.

Tabel 2.1 Simbol Use Case Diagram

\begin{tabular}{|c|c|c|}
\hline No & Simbol & Keterangan \\
\hline 1 & & $\begin{array}{lr}\text { Actor } & \text { merupakan } \\
\text { bagian } & \text { dari } \\
\text { UseCase } & \text { yang } \\
\text { bertindak } & \text { sebagi } \\
\text { subjek } & \text { (pelaku) } \\
\text { dalam } & \text { suatu } \\
\text { proses. } & \end{array}$ \\
\hline 2 & & $\begin{array}{l}\text { UseCase } \\
\text { merupakan } \\
\text { penggambaran } \\
\text { proses yang } \\
\text { dilakukan oleh } \\
\text { Aktor terhadap } \\
\text { sitem }\end{array}$ \\
\hline 3 & & $\begin{array}{l}\text { Relasi } \\
\text { menggambarkan } \\
\text { hubungan antara } \\
\text { Aktor dan Use } \\
\text { Case. }\end{array}$ \\
\hline 4 & & $\begin{array}{l}\text { Communication } \\
\text { merupakan } \\
\text { hubungan Actor } \\
\text { dengan jenis } \\
\text { interaksinya } \\
\text { dengan sistem }\end{array}$ \\
\hline
\end{tabular}

3. Pengujian Sistem dengan Blackbox

Pengujian ini dimaksudkan untuk mengetahui apakah perangkat lunak yang dibuat telah memenuhi tujuan dari perancangan perangkat lunak itu sendiri. Sebelum penerapan sistem, terlebih dahulu harus dipastikan bahwa sistem telah bebas dari kesalahan logika yang mungkin dapat terjadi agar sesuai dengan harapan pengembang aplikasi dalam pembuatan aplikasi sistem informasi akademik berbasis mobile.

\section{HASIL}

\section{A. Analisis Kebutuhan Sistem}

Ada beberapa kebutuhan sistem yang harus diperhatikan dalam merancang sebuah sistem yaitu:

\section{Kebutuhanfungsional (functional} requirement)

a. sistem mampu menampilkan data mahasiswa

Mahasiswa dapat melihat data pribadi diri dan dapat mencari data mahasiswa lain.

b. Sistem mampu menampilkan Kartu Hasil Studi (KHS)

Mahasiswa dapat mengakses Kartu hasil studi (KHS)

b. Sistem mampu menampilkan Kartu Hasil Studi (KRS)

Mahasiswa dapat melihat KRS persemester berjalan serta KRS sebelumnya.

c. Sistem mampu menampilkan Transkip Nilai

Mahasiswa dapat melihat Transkip Nilai secara keseluruhan.

d. Sistem mampu mengubah akun

Mahasiswa dapat mengubah akun password yang telah disediakan.

2. Kebutuhan non fungsional (non functional requirement)

a. Operasional 
1) kebutuhan Smartphone android yang digunakan minimal 2.3 Gingerbread

2) kebutuhan Memori Ram minimal 512 $\mathrm{MB}$

3) Processor yang digunakan minimal 1.2.Ghz.

b. Keamanan

1.) Sistem dilengkapi dengan password yang akan digunakan mahasiswa.

2) Password yang ada dalam sistem telah terdaftar

3) Mahasiswa tidak dapat mengubah data KHS,KRS,TN kecuali admin tetapi dapat mengubah data akun.

4) Mahasiswayang login memiliki account yang telah terdaftar dan dapat mengakses halaman Dashboard

B. Perancangan Diagram Model Data

Berikut perancangan Diagram Model sistem dalam pembuatan sistem informasi akademik berbasis mobile yang akan menjelaskan beberapa cara kerja dari sistem dan fungsi masing-masing antara actor dan pekerjaannya adalah :

\section{Use Case Sistem}

Use Case sistem berisi
pekerjaan-pekerjaan yang akan
dilakukan seorang aktor dimana dia
yang akan mengawasi dan mengelola
data yang ada pada sistem dalam hal
ini adalah seorang admin dan
Mahasiswa sebagai aktor yang
mengakses informasi

a. Use Case sistem informasi akademik (SIAKAD)

$$
\text { Gambar } 3.6 \text { merupakan }
$$

pekerjaan yang dilakukan oleh Sistem

Informasi Akademik.

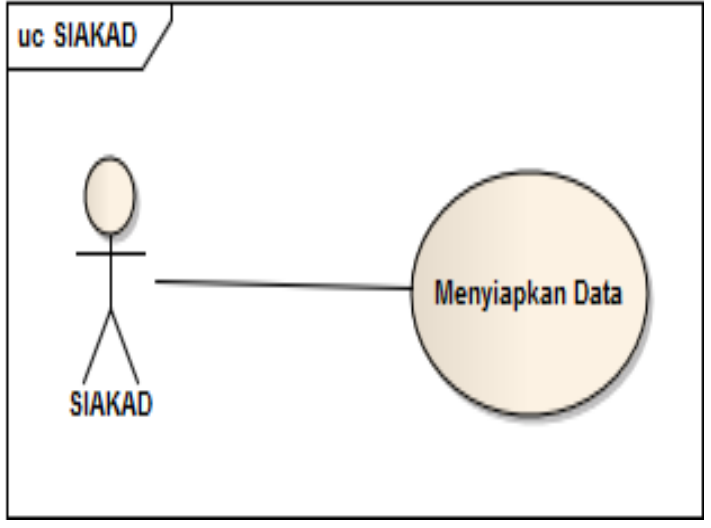

\section{Gambar. 3.6. Use Case SIAKAD}

b. Use Case Sistem Mahasiswa

Gambar 3.6. dibawah ini merupakan beberapa kegiatan yang akan dilakukan oleh Mahasiswa.

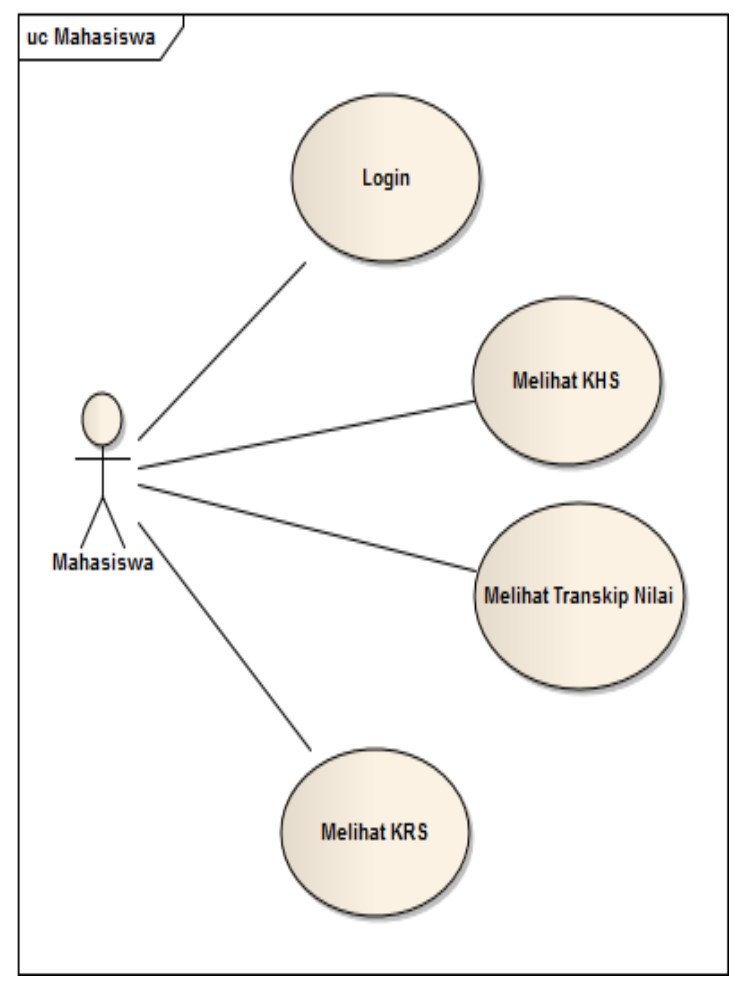

Gambar 3.7. Use Case Mahasiswa

\section{Activity Diagram}

Digunakan untuk memodelkan aspek dinamis dari sistem Activity Diagram secara esensial dan 
memperlihatkan aliran kendali dari suatu aktifitas lainnya.

a. Diagram Activity SIAKAD

Pada gambar 3.8 dibawahdapat dilihat activitypengambilan data dari SIAKAD Stikes Nanidilakukandengan proses parsing data JSONke android danmenampilkan data dari SIAKAD ke Android

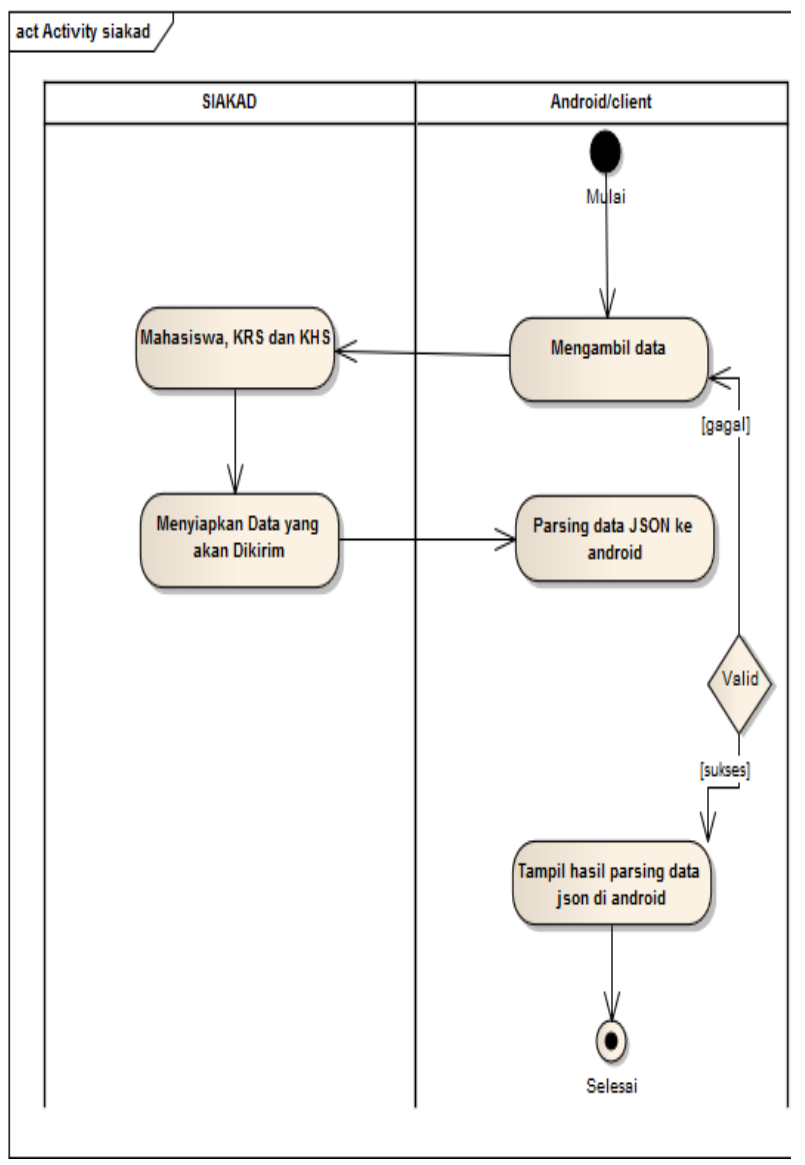

Gambar 3.8. Use Case SIAKAD

\section{Perancangan Interface Desain Sistem}

Tampilan atau Interface sistem informasi akademik STIKES NANI berbasis mobile harus dapat dengan mudah dipahami oleh pengguna terutama kalangan mahasiswa, selain inputan data yang benar salah satu hal yang menjadi pendukung kedua suksesnya sebuah sistem yaitu interface yang mudah dipahami. Berikut beberapa interface perancangan sistemnya :

\section{TampilanHalaman Login.}

Pada halaman ini mahasiswa diwajibkan menginputkan nim dan password yang telah disediakan oleh admin sehingga pengguna dapat mengakses menu utama.

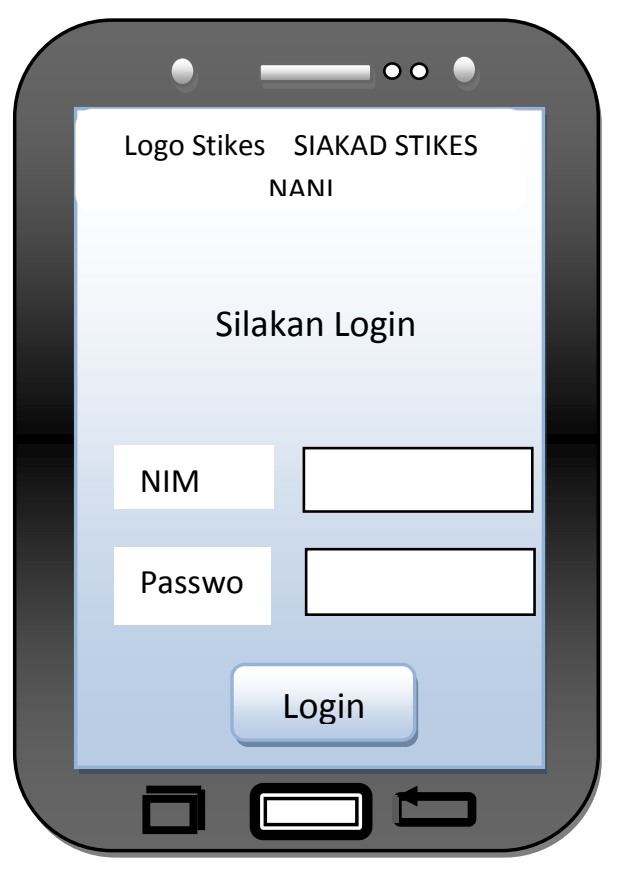

\section{Gambar 3.15Tampilanhalaman login}

\section{PEMBAHASAN}

\section{A. Implementasi Sistem Informasi}

\section{Menurut Bayuntara}

(2012)

Implementasi adalah suatu tindakan atau pelaksanaan dari sebuah rencana yang sudah disusun secara matang dan terperinci. Implementasi biasanya dilakukan setelah perencanaaan sudah dianggap sempurna.

Menurut Hutahaean (2014: 2)sistem adalah suatu jaringan kerja dari prosedurprosedur yang saling berhubungan, yang 
bekumpul bersama untuk melakukan kegiatan atau untuk melakukan sasaran tertentu.

Selain merupakan sumber daya informasi di kampus, SIAKAD juga dapat digunakan sebagai sarana media komunikasi antar dosen dan mahasiswa dilingkungan kampus menggunakan teknologi internet sehingga akses informasi akademik tidak hanya dapat dilakukan di dalam kampus saja tetapi diluar kampus pun bisa bahkan diamana saja selama terhubung dengan jaringan internet.

\section{B. Karakteristik Sistem Informasi}

Menurut Fatta (2007 : 5), untuk memahami atau mengembangkan suatu sistem maka perlu menebedakan unsurunsur dari sistem yang membentuknya. Berikutnya adalah karakteristik sistem yang dapat membedakan suatu sistem dengan sistem lainnya:

b. Batasan (boundary)

Pengambaran dari suatu elemen atau unsur mana yang termasuk di dalam sistem dan mana di luar sistem.

c. Lingkungan (environment) Segala sesuatu di luar sistem, lingkungan yang menyediakan asumsi, kendala, dan input terhadap suatu sistem.

d. Masukan (input)

Sumberdaya (data, bahanbaku, peralatan, energy) dari lingkungan yang dikonsumsi dan dimanipulasi oleh suatu sistem.

e. Keluaran (output)

Sumber daya atauproduk (informasi, laporan, dokumen, tampilan layer komputer, barang jadi) yang disediakan untuk komponen sistem oleh kegiatan dalam suatu sistem. f. Komponen (component)

Kegiatan-kegiatanatau proses dalam suatu sistem yang menstransformasikan input menjadi bentuk setengah jadi (output). Komponen ini merupakan subsistem dari sebuah subsistem.

g. Penghung (interface)

Tempat dimana komponen atau sistem dan lingkungannya bertemu atau berinteraksi.

h. Penyimpanan (storage)

Area yang dikuasai dan digunakan untuk penyimpanan sementara dan tetap dari informasi, energi, bahanbaku, dan sebagainya. Penyimpanan merupakan suatu media penyangga diantara komponenter sebut bekerja dengan berbagai tingkatan yang ada dan memungkinkan komponen yang berbeda dari berbagai data yang sama.

\section{Sistem Informasi Akademik}

Sistem Informasi Akademik (SIAKAD) Menurut Nuari(2013), adalah aplikasi atau sistem yang dirancang dan dibuat untuk mengelolah data-data yang berhubungan dengan informasi akademik, meliputi data mahasiswa, data dosen, rekaman hasil kuliah, kurikulum dan jadwal perkuliahan.

\section{Mobile OS (Mobile Operation System)}

Sistem operasi mobile dikenal dengan sebutan platform, perangkat lunak untuk mobile, sistem operasi genggam adalah sebuah program yang menggerakan suatu perangkat keras seperti ponsel, smartphone, PDA, komputer tablet, perangkat informasi dan lain sebagainya. 


\section{E. Versi Android}

Android adalah sebuah sistem operasi berbasis linux untuk perangkat mobile yang mencakup sistem operasi, middleware dan aplikasi.

Menurut Sari Adapunversi-versi android yang pernahdirilisadalahsebagaiberikut:
a. Android 1.1 Bender
b. Android 1.5 Cupcake
c. Android 1.6 Donut
d. Android 2.0/2.1 Éclair
e. Android 2.2 Froyo (Froze Yoghurt)
f. Android 2.3 Gingerbread
g. Android 3.0/3.1 Honeycomb
h. Android 4.0 ICS (Ice Cream Sandwidch)
i. Android versi 4.1 (Jelly Bean)
j. Android versi 4.2 (Jelly Bean)

\section{F. Web Service}

Menurut Nuari (2013: 3) Web service adalah suatu sistem perangkat lunak yang dirancang untuk mendukung interoperabilitas dan interaksi antar sistem pada suatu jaringan.

\section{G. Web Server Xampp}

Menurut Hidayatullah (2014:125-128) dalam mengatakan bahwa untuk menguji apakahaplikasi web anda berjalan dengan baik atau tidak maka diperlukan yang disebut Web server.

\section{E. JSON (Java Script Object Notation) MenurutRizaldi (2010) JSON} (JavaScript Object Notation) adalah sebuah format penulisan untuk pertukaran data (data-interchange) yang ringan. Sangat mudah bagi manusia untuk membaca dan menuliskannya. Semudah mesin memparsing dan men-generate format datanya. JSON mampumelakukanpemindahan data antara dua interface dengan sangat cepat dan powerfull (misalnya antara php dengan JavaScript) (Ratmelia, 2014).

JSON merupakan struktur data yang universal, dalam artian bisa digunakan dalam berbagai bahasa pemrograman. Hampir semua bahasa pemrograman mendukung penuh JSON dalam berbagai

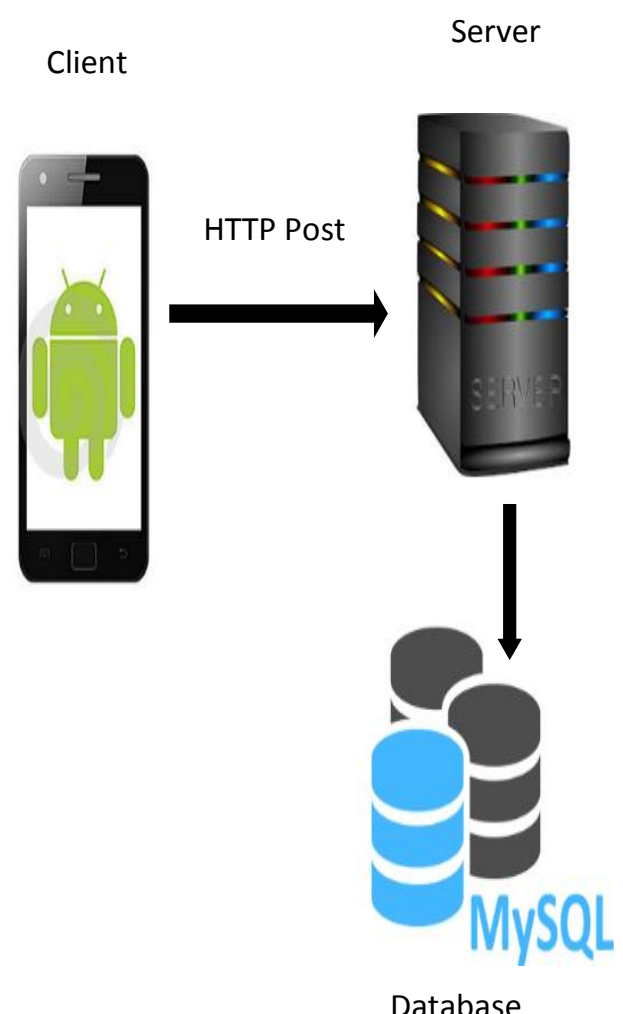

format. Hal ini memungkinkan format data yang dapat dipertukarkan menggunakan bahasa pemrograman juga menggunakan dasar dari struktur JSON. JSON sangat berguna saat kita sering melakukan pertukaran data pada sebuah aplikasi. Plugin ini juga mendukung format JSON, selain format XML. Sebagai contoh adalah, menghubungkan antara PHP (server) dengan Android (client) menggunakan HTTP dan JSON, seeprti pada gambar berikut ini:

Gambar2.16.Skema Android- Server MySQL menggunakan JSON 


\section{SIMPULAN DAN SARAN}

\section{A. KESIMPULAN}

Adapun kesimpulan dari penelitian yang berjudul "Implementasi Web Service dalam pengembangan Sistem Informasi Akademik Berbasis Mobile Pada STIKES NANI" adalah sebagai berikut :

1. Perancangan Aplikasi SIAKAD yang dirancang dengan menggunakan sistem Mobile khususnya android sebagai salah satu media dalam memberikan informasi akademik di lingkungan kampus STIKES NANI kepada mahasiswa dengan pemanfaatan mobile computing. Mahasiswa dapat melihat krs, khs dan transkrip nilai.

2. Hasil implementasi dari aplikasi SIAKAD ini menunjukkan bahwa aplikasi dapat berjalan dengan baik dengan pengisian kuesioner pengujian aplikasi mendapatkan hasil pengujian dari sistem yang dirancang dan dinyatakan layak dan secara fungsional sistem dapat menghasilkan output yang diharapkan.

\section{B. SARAN}

Sistem yang dibangun masih memiliki beberapa kekurangan, oleh karena itu ada beberapa hal yang perlu dikembangkan agar menjadi lebih baik, antara lain :

1. Adanya pemberitahuan (notification) update nilai terbaru sehingga pengguna dapat mengetahui informasi baru telah masuk dalam aplikasi.

2. Diharapkan pengembangan selanjutnya nilai dari matakuliah dapat ditampilkan dalam bentuk pdf sehingga mudah untuk didownload para pengguna aplikasi khususnya mahasiswa.

3. Pengembangan dari aplikasi SIAKAD STIKES NANI (Sistem Informasi Akademik)diharapkan dapat berjalan diseluruh platform bukan hanya pada smartphone bersistemoperasi android saja.

\section{REFERENSI}

[1]. Arianto.Hidayat Rahmat. 2006. "seri01 Belajar Database Mysql". http://akuntansi.polines.ac.id/akuntans $\mathrm{i} /$ sites/default/files/downloa d/mysqlrahmat.pdf. Diakses Tanggal 27 Desember 2016.

[2]. Al Fatta, H. (2007). Analisis dan Perancangan Sistem Informasi untuk Keunggulan Bersaing Perusahaan dan Organisasi Modern. Yogyakarta: Andi.

[3]. Bayuntara. 2012. "Bab II Kajian Pustaka A. Pengertian Implementasi”. http://digilib.ump.ac.id/files/disk1/14/j hptump-a-bayutantra-660-2-

babii.pdf'. Diakses Pada Tanggal 27 Desember 2016.

[4]. Budiawan. 2013." Rancang Bangun Game Sederhana Dengan Rest Web Service Yang Diterapkan Pada Sistem Operasi

Android". http://eprints.dinus.ac.id/12633/1/jurn al_12781.pdf. Diakses pada tanggal 8 januari 2017.

[5]. Fitriyanti, Nurul. 2011. “ Rancang Bagun Sistem Akademik Berbasis Web".http://repository.uinjkt.ac.id/dsp 
ace/bitstream/123456789/3114/1/N

URUL\%20FITRIYANI-FST.pdf.

Diakses pada tanggal 27 Desember 2016.

[6]. H, Nazruddin Safaat. 2012. “Android Pemrograman Aplikasi Mobile Smartpnone dan Tablet PC Berbasis Android". Bandung : Informatika Bandung, 2012.

[7]. H, Nazruddin Safaat. 2015. "Android Pemrograman Aplikasi Mobile Smartpnone dan Tablet PC Berbasis Android Revisi Kedua".Bandung : Informatika Bandung, 2015.

[8]. Hutahaean, J. (2014). Konsep Sistem Informasi. Yogyakarta: Deepublish.

[9]. Jogiyanto.2005."analisis dan desain. Yogyakarta. andi Kadir, Abdul. 2003."Konsep \& Tuntunan Praktis Basis Data”. Yogyakarta. Andi.

[10]. Martinus Raditia Sigit Surendra. 2014. "Implementasi PHP Web Service Sebagai Penyedia Data Aplikasi Mobile"

http://library.umn.ac.id/jurnal/public/u ploads/papers/pdf/83cbb700e c779db3f9f04471dbc9z9c71.pdf.

Diakses pada tanggal 27 desember 2016.

[11]. Nicky Rolly dan Nashrul Hakiem. 2015. " Pengembangan Aplikasi Mobile

Academic Information System (Ais) Berbasis Android Untuk Pengguna Dosen Dan Mahasiswa (Studi Kasus : Pusat Teknologi Informasi Dan Pangkalan Data (Pustipanda) Uin Syarif'. http://www.ejurnal.com/2015/11/pengembanganaplikasi-mobileacademic.html. Diakses Tanggal 8 Januari 2017.

[12]. Nuari, Novi. 2013. Perancangan Aplikasi Layanan Mobile Informasi
Administrasi Akademik Berbasis Android Menggunakan Webservice (Studi Kasus Reg.B Universitas Tanjungpura).

http://jurnal.untan.ac.id/index.php/just in/article/download/4523/461 6. Di akses Tanggal 9 Januari 2017.

[13]. Paksi, Angger Binuko. 2014. "Implementasi Web Service Untuk Perancangan Aplikasi Zoopedia Berbasis Android". http://repository.amikom.ac.id/files/Pu blikasi_10.11.3583.pdf". Diakses Tanggal 28 Desember 2016.

[14]. Priyanto, H., \& Kawistara, J. K. (2014). Pemrograman Web. Bandung: Informatika Sari, maulida arta. 2013. "Boomingya android". 2013. http://ilmukomputer.org/2013/04/25/b oomingnya-android/.diakes tanggal 27 Desember 2016.

[15]. Sutabri, Tata. 2004. “ Analisa Sistem Informasi”. Yogyakarta. Andi Utama,Yadi."Definisi Web Service”. http://lecturer.ukdw.ac.id/ mahas/doss ier/ati_04.pdf. diakses tanggal 29 Desember 2016.

[16]. Wellem ,Theophilus. 2009. "Perancangan Prototype Aplikasi Mobile UntukPengaksesan Web Service". http://repository.upnyk.ac.id/295/1/E1 6_TheophilusWellem_WebService_F TIUKSW.pdf. Diakses 10 Januari 2017.

[17]. Lucky. (2008). XML Web Service: Aplikasi Desktop, Internet \& Handphone. Jakarta: Jasakom.

[18]. Ratmelia, L. (2014). Membangun Aplikasi Android Untuk Sistem Akademik (Studi Kasus : Fakultas Sains dan Teknologi UIN Suska Riau). Universitas Islam Negeri Sultan Syarif Kasim Riau. Skripsi. 
Sulehu, Implementasi Web Service Dalam Pengembangan Sistem Informasi Akademik Berbasis Maobile Pada STIKES Nani Hasaanuddin Makassar 